Journal Homepage: : http://www.razipublishing.com/journals/malaysian- journalofsustainable-agriculture-mjsa/

https://doi.org/10.26480/mjsa.02.2017.01

SHORT COMMUNICATION

\title{
ELECTRICAL STIMULATION FOR EGGS AND SEMEN ON TACHYPLEUS TRIDENTATUS COLLECTED FROM LOCAL RESTAURANTS IN HONG KONG
}

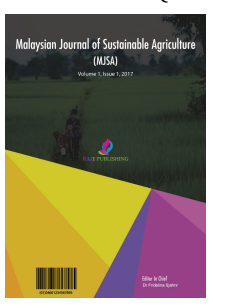

Yh Cheung, Oy Lam, Sc Lun, Ch Pang, Kw Wu, Wk Leung

Po Leung Kuk Laws Foundation College, Hong Kong

This is an open access article distributed under the Creative Commons Attribution License, which permits unrestricted use, distribution, and reproduction in any medium, provided the original work is properly cited

\section{ARTICLE DETAILS}

Article history:

Received 12 September 2017

Accepted 19 October 2017

Available online 30 October 2017

The major threats of horseshoe crabs in Hong Kong include (1) coastal development, whichdestroys the sprawling grounds of horseshoe crabs; and (2) fisheries, which reduces its populationin the wild directly. Artificial breeding of juvenile horseshoe crabs for wild release is therefore considered as one of the means to raise the population of this species.

However, due to a very low population of wild mature and reproductive horseshoe crabs in Hong Kong, a stable supply of eggs and semen is often an obstacle in the commencing artificial breeding. In the present study, with the support of a local restaurant, six Tachypleus tridentatus were borrowed for electrical stimulation for eggs and semen. These horseshoe crabs were caught in sea by fishermen and sold together with other seafood to restaurants. After electrical stimulation, the horseshoe crabs were returned to the restaurant to continue their display as an attraction to customers (consumption of horseshoe crabs is not common).

Undoubtedly, this is not an ideal conservation method. However, with no regulation of law in preventing fishing, trading and consumption of horseshoe crabs, collaboration with restaurants for a relatively stable supply of mature and reproductive horseshoe crabs is a possible solution satisfying both needs: Restaurants have no real loss, whereas more juvenile horseshoe crabs can be bred artificially and eventually released to the wild. 